\title{
Basics of modeling and technology of creating reinforced concrete elements of "Monofant" system construction
}

\author{
Sergey Bugayevskiy ${ }^{*}$, Vladymir Gerasymenko², Alexander Konyukhov ${ }^{3}$, and Valeriy \\ Nikulin $^{3}$ \\ ${ }^{1}$ Kharkiv National Automobile and Highway University, Department of Bridges, constructions and \\ structural mechanics, 61002 Kharkiv, Yaroslav Mudry st., 25, Ukraine \\ ${ }^{2}$ Kharkiv National University of Civil Engineering and Architecture, Department of Graphs, 61002 \\ Sumska str., 40, Kharkiv, Ukraine \\ ${ }^{3}$ Zhilbud-2 Company in Kharkiv, Company management, 61145 Kharkiv, Space Str., 12, Ukraine
}

\begin{abstract}
In architectural and construction system "Monofant" a selfsupporting skeleton consisting of a spatial curvilinear framework and unrecoverable hollow-core inserts made of expanded polystyrene was used to erect buildings and structures of curved shapes from reinforced concrete lightweight structures. For this, an internal, non-removable formwork of complex shape makes up given geometry of the structure and becomes a certain screen on which a shotcrete mixture is sprayed. The problem of creating a technology for manufacturing polystyrene inserts for the erection of cylindrical shells has been solved. At the same time we achieved reducing the waste while cutting a flat rectangular sheet of expanded polystyrene and obtaining the minimum number of elements in the assortment for manufacturing triangular inserts used to produce a screen that provides shotcreting curvilinear reinforced concrete structures with the method of sprayed concreting. The obtained results confirm the effectiveness of using lightweight "Monofant" system designs that have a reduced width of not more than $40-50 \%$ from the structures with solid width.
\end{abstract}

\section{Introduction}

The idea of optimizing the shape of the cavities and increasing the dimensions of voids in reinforced concrete products and structures remains one of the most dominant concepts of reducing the material consumption of buildings and structures. Its implementation is related to both computationally constructive and technological problems. Application of nonextractable inserts-cavities in the technology of producing reinforced concrete lightweight structures allows to reduce the weight of structures by $20-40 \%$ without reducing their strength characteristics. In the result of introducing more complicated process of manufacturing reinforced concrete lightweight structures in comparison with solid crosssection, minimizing the cost of manufacturing liners, due to the use of recycled plastics or the use of cheap materials still remains a highly important problem.

\footnotetext{
*Corresponding author: bugaevskiysa@gmail.com.
} 


\section{Analysis of publications}

In the global practice, unified volumetric modules made of polymer materials of various shapes are widely used as non-extractable insert-fillers in the technologies of production of reinforced concrete lightweight structures [1-4]. Due to the lack of the necessary production facilities they cannot be commonly used in the Ukrainian civil engineering.

The arrangement of liners inside concrete and reinforced concrete structures and products is strictly regulated, and in most cases is connected with the construction of spatial reinforcement skeletons or with one of the dimensions of a structure or product, for example, with the width of the overlap. Accordingly, the size of the liner (diameter) of a spherical shape is determined from the condition providing two widths of the protective overlap layer. In general, the unified arrangement of the same type of liners is used when concreting a building or any other construction, which in most cases does not ensure the rationality of creating the internal geometry of lightweight structures (the shape of internal ribs, their width and pitch).

An alternative approach is the use of expanded polystyrene as the most economically justified material for the manufacture of hollow-forming agents $[5,6]$. The production of void-formers can be performed according to given geometric parameters or by cutting a necessary form from expanded polystyrene blocks. However, in our opinion, it doesn't solve the problem of creating liners for reinforced concrete lightweight structures with a surface which differs from the surface of zero Gaussian curvature and manufactured by non-traditional methods of concreting with the use of vibration, but by methods of pneumatic spraying (shotcreting).

The architectural and construction system "Monofant" [7, 8] was developed in Ukraine under the guidance of prof. V.S. Shmukler. In it a self-supporting skeleton consisting of a spatial curvilinear framework and unrecoverable hollow-core inserts made of expanded polystyrene or mineral wool was used to erect buildings and structures of curved shapes from reinforced concrete lightweight structures. For this, an internal, non-removable formwork of complex shape makes up given geometry of the structure and becomes a certain screen on which a shotcrete mixture is sprayed onto both sides with the help of a wet shotcreting method. To create a solid screen, the gaps between the liners that form internal ribs of lightweight structures, are closed on one side with grids, e.g. wire mesh or with a perforated sheet. The uniqueness of the suggested method of erecting such structures is confirmed by the Ukrainian patent for the invention [9].

Geometric shape of the reinforced concrete lightweight structure influences the geometry of the internal non-removable formwork.

\section{The purpose and objective of the problem}

The purpose of this work is modeling and technology of producing an internal nonremovable formwork for concreting curved lightweight structures made of reinforced concrete on the "Monofant" system.

The objective of the study is determining the shape of the inserts and their production from expanded polystyrene for erecting reinforced concrete lightweight structures of cylindrical form.

\section{Determination of the shape and creation of a cavity-maker}

Various architectural sites can be constructed using reinforced concrete lightweight cylindrical structures without applying an expensive individual formwork (Figure 1). 
The manufacturing technology of reinforced concrete structures with curvilinear shape described in the article was tested while erecting a planned fragment of a $2.2 \times 2.2 \mathrm{~m}$ cylindrical shell (Figure 2). The width of the reinforced concrete shell was $26 \mathrm{~cm}$, where 16 $\mathrm{cm}$ stand only for the width of the non-removable hollow-core inserts made of expanded polystyrene, and $5 \mathrm{~cm}$ from the outer and inner sides - for the reinforced concrete bindings.

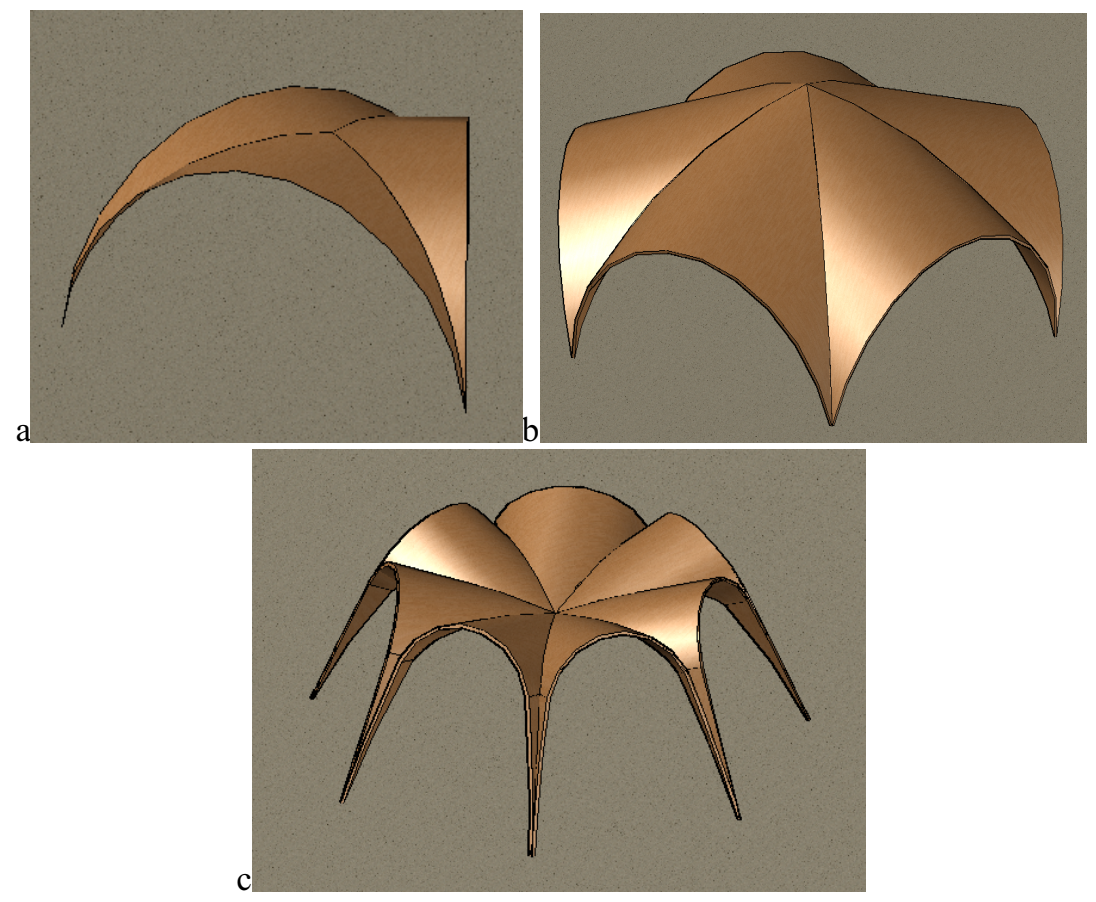

Fig. 1. Bearing structure of interpenetrating cylindrical surfaces: $a$ - three surfaces; $b$ - five surfaces; $\mathrm{c}-$ seven surfaces.

The choice of geometric and typological characteristics of non-extractable void generators for producing reinforced concrete structures and products should be made considering the optimization of design and technological solutions. For those certain requirements for ensuring the strength of lateral and internal ribs to shear along the inclined and longitudinal sections must be observed; elimination of stress concentration in the areas of conjugation of the shelf and ribs; requirements to ensure rigidity and crack resistance in normal and inclined sections, and, finally, fulfillment of all structural requirements for maintenance with the protective layer.

To make a curvilinear-shaped insert of the construction, we are offering a method for its production from individual flat elements that can be cut from a rectangular flat sheet of expanded polystyrene with a machine tool (Figure 2, a).

At the same time, the main issue is reducing the waste when cutting a flat rectangular sheet of expanded polystyrene and the maximum reduction in the number of elements in the assortment for the manufacture of the liner used as a non-removable formwork of cylindrical shape. When constructing the diagonally inner edges of the shell, four inserts of two type sizes should be made (Figure 3 ).

The cabbling of each insert individually into compound elements of a secant parallel to one of the sides of the shell will result in a large number of types of elements with the same shape, but different length ranging from 230 to $2030 \mathrm{~mm}$. When dividing each liner with a secant parallel or perpendicular to the larger side of the liner, we get an even larger increase in the types of elements and their clear separation for two types of liner size (Figures 4, 5). 

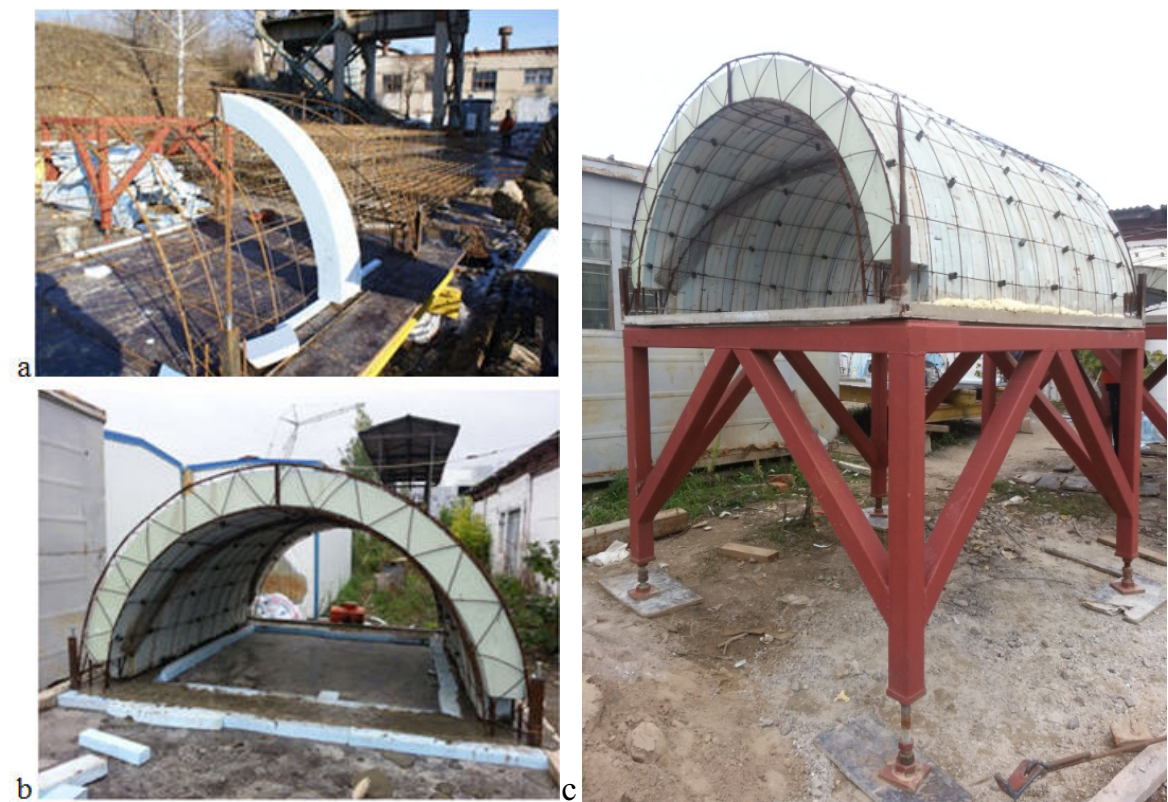

Fig. 2. Manufacturing a self-supporting skeleton: $\mathrm{a}-$ an element of the liner; $\mathrm{b}$ and $\mathrm{c}-$ the construction of the skeleton.

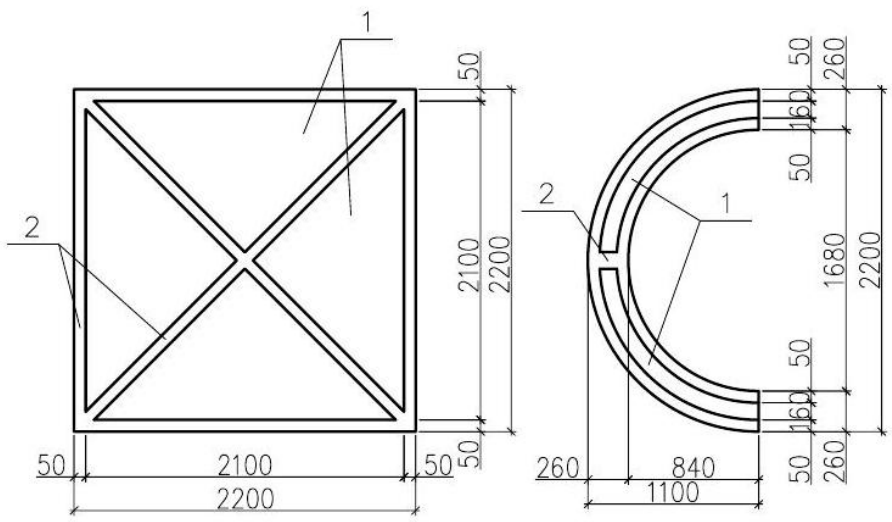

Fig. 3. Shape of liners in a cylindrical shell: 1 - insert; 2 - internal ribs.

To optimize the cutting of the inserts, we are offering an option for the production of four inserts at once as a single whole liner, followed by cutting it into four parts diagonally (Figures 6,7). This cutting option allows you to reduce the number of sizes up to two elements.

When cutting along the shell, all elements of a rectangular outline with the length of $2100 \mathrm{~mm}$ (two types of size) are obtained, but both with a trapezoidal cross section, which will require additional cutting operations on each individual element. The disadvantage of the final prefabrication of a non-removable formwork is the possible significant deviation in the shape of the resulting structure from a cylindrical one and the additional use of templates to correct inaccuracies connected with the peculiarities of making liners in this way. 

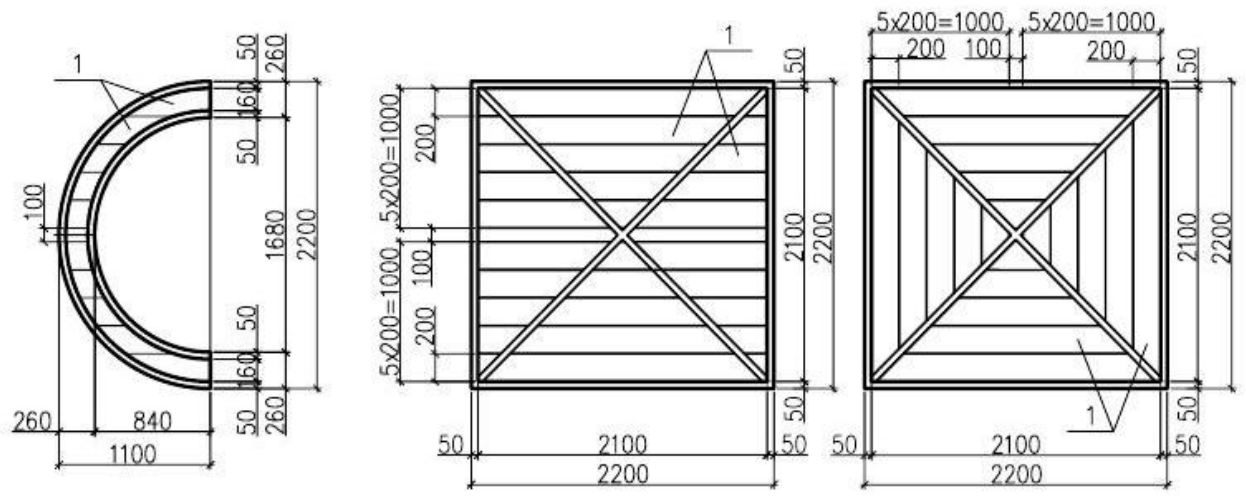

Fig. 4. Cutting each liner separately (option 1): 1 - types of liner elements.
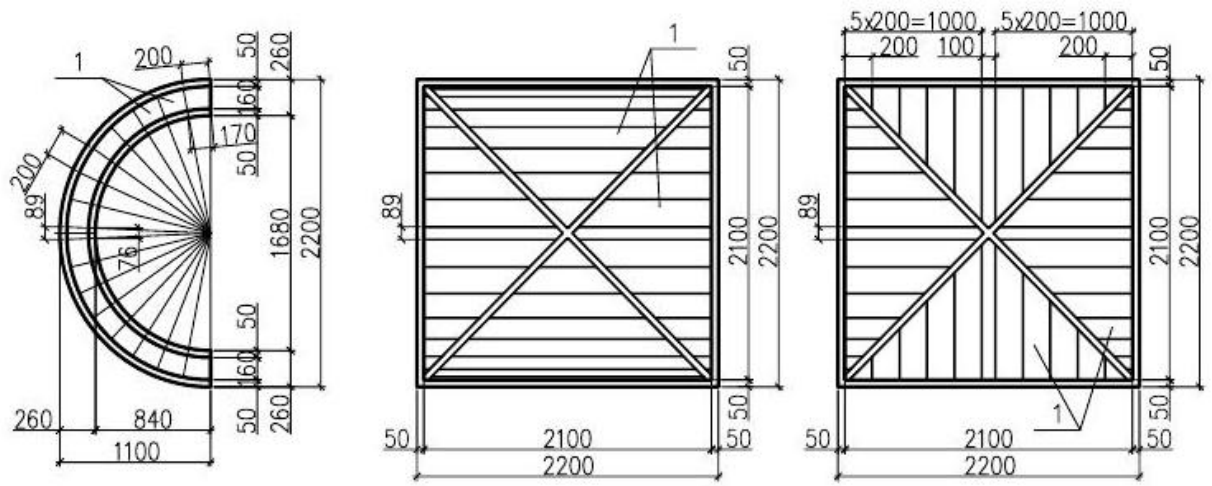

Fig. 5. Cutting each liner separately (option 2): 1 - types of liner elements.
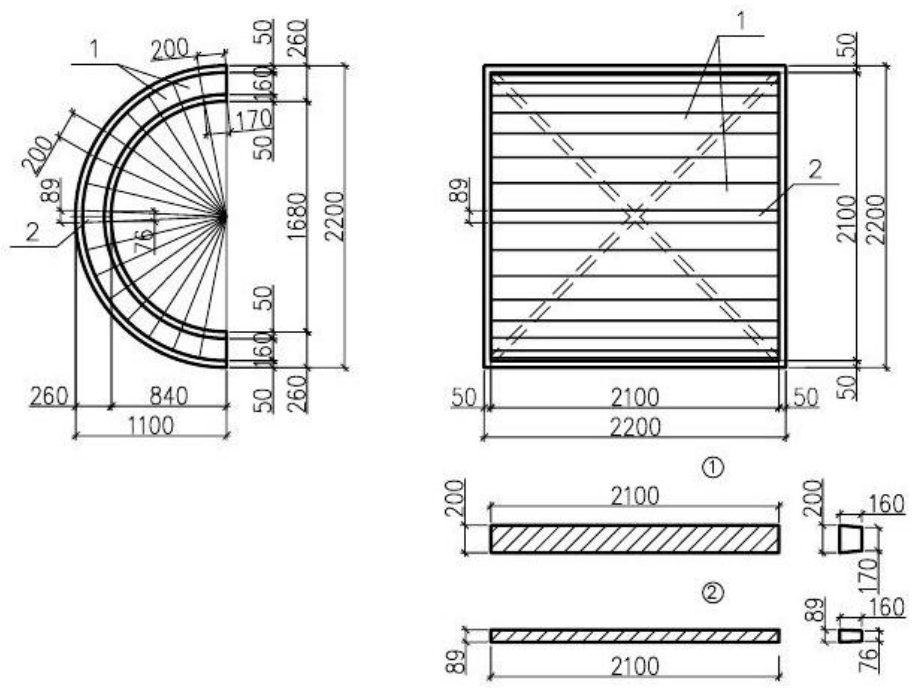

Fig. 6. Cutting four liners as a single element (alongside) 1,2-types of liner elements. 

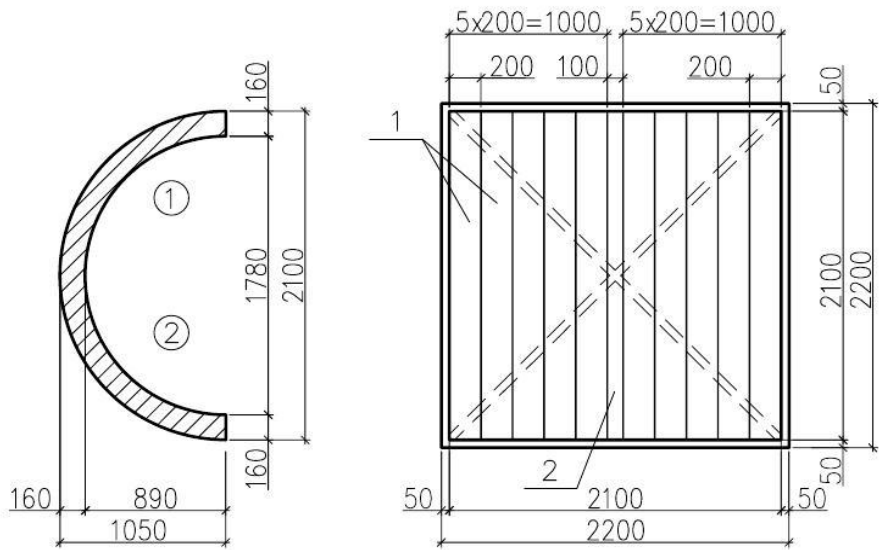

Fig. 7. Cutting four liners as a whole element (crosswise): 1,2 - types of liner elements.

When cutting across the shell, the elements into which the non-removable formwork is divided have a plan dimension of $1050 \times 2100 \mathrm{~mm}$ and a significant curvature, which results in a large waste of materials during their manufacture (Figure 8). At the final prefabrication of the non-removable formwork, the accuracy of manufacturing cylindrical liners is ensured.

To optimize the cutting of elements with the planned dimension of $1050 \times 2100 \mathrm{~mm}$, an additional cabbling of them into parts $1 / 2$ and $1 / 4$ of the arc length is suggested (Figure 9).

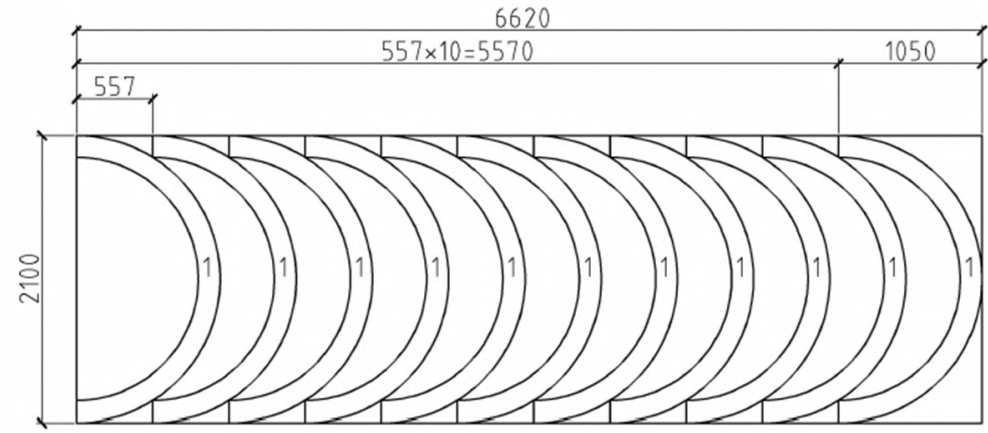

Fig. 8. Layout of solid elements.

Interchange in the prefabrication of fixed formwork elements $2+2$ and $3+2+3$ will ensure that the seams do not fit as well as the integrity of the structure made of expanded polystyrene.

The next option of cabling the inserts in the radial direction (Figure 10), will further reduce the consumption of materials. Assembling liners of non-removable formwork with alternating elements $4+5+6,5+6+4,6+4+5$, will ensure the overlap of seams through three rows of segments. The lap length of the seams can be calculated from the length of the chord $L$ :

$$
L=2 R(\sin \alpha / 2)
$$

where $R$ - radius of a circle; $\alpha$ - central angle. 

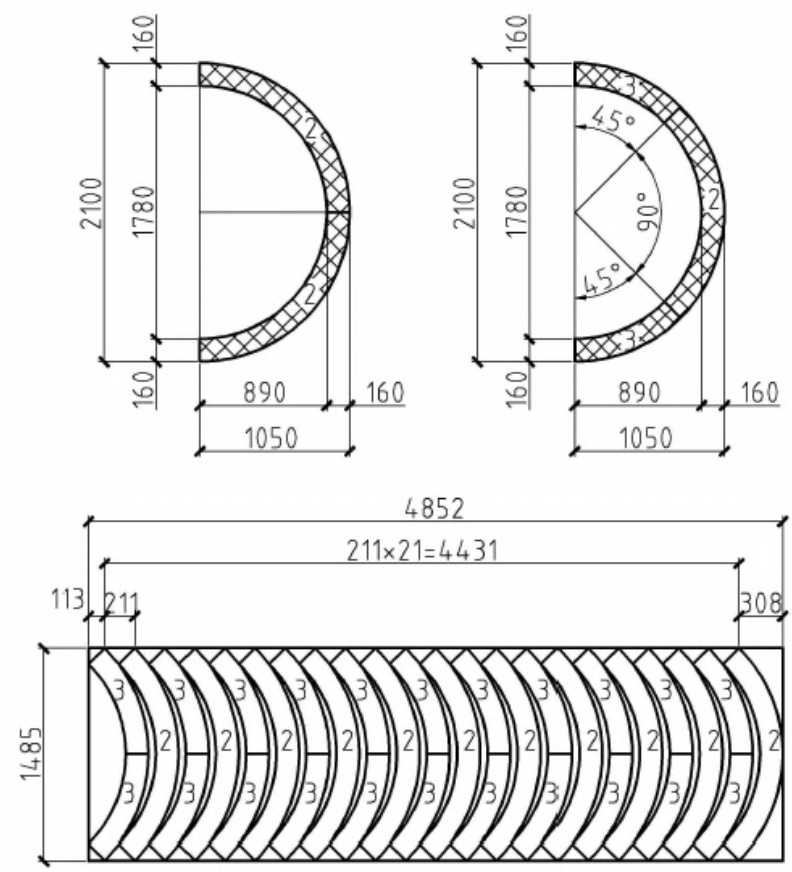

Fig. 9. Layout of compound elements: 2, 3-types of liner insert elements.
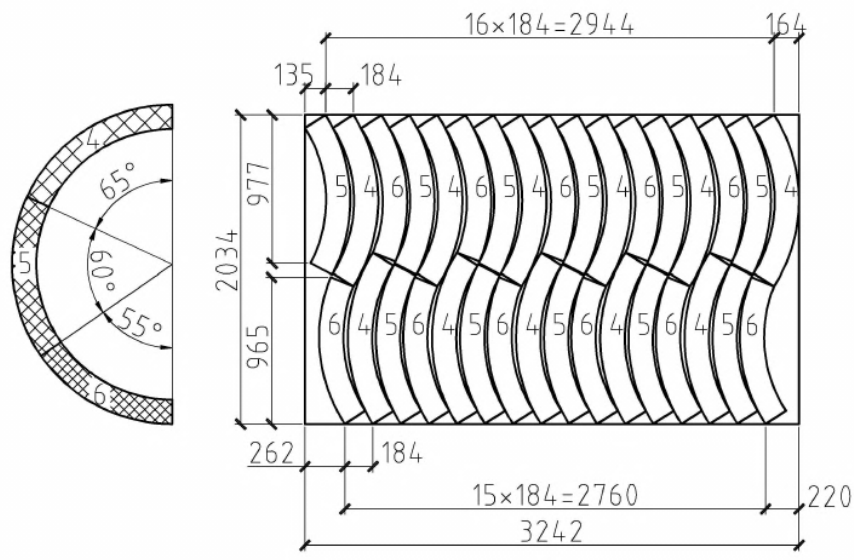

Fig. 10. Layout of compound elements: 4, 5,6-types of liner insert elements.

The options of cabling into elements (Figures 9, 10) significantly reduce the cost of material when cutting a sheet of expanded polystyrene of a rectangular shape (Table 1).

As it can be seen on Table 1, the cutting of liners according to Figure 10 is more economical in terms of material consumption and packing density.

In order to unify the production of liners during the erection of constructions on the "Monofant" system, we're offering production of a prismatic body tiling with multifaceted elements in the shape of a truncated pyramid with a base in the shape of regular polygons. There are three correct tilings of the plain: triangular parquet, square parquet and hexagonal parquet (Figure 11). 
Table 1. Areas of void generators and waste in the process of cutting liner inserts from a rectangular sheet.

\begin{tabular}{|c|c|c|c|c|c|}
\hline 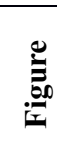 & $\begin{array}{c}\text { Dimensions of } \\
\text { expanded polystyrene } \\
\text { sheet }(b \times h)=\text { area, } \\
m \times m=m^{2}\end{array}$ & $\begin{array}{c}\text { Insert } \\
\text { element / } \\
\text { amount }\end{array}$ & $\begin{array}{c}\text { The area of one } \\
\text { insert/ the area of } \\
\text { inserts of this } \\
\text { position, } \mathrm{m}^{2} / \mathrm{m}^{2}\end{array}$ & $\begin{array}{c}\text { Waste } \\
\text { area, } \\
\text { m }^{2}\end{array}$ & 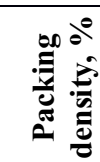 \\
\hline 8 & $6.621 \times 2.1=13.9$ & $1 / 11$ & $0.487 / 5.363$ & 8.54 & 38.58 \\
\hline \multirow{2}{*}{9} & \multirow{2}{*}{$4.855 \times 1.485=7.21$} & $2 / 11$ & $0.244 / 2.682$ & \multirow{2}{*}{1.85} & \multirow[b]{2}{*}{74.5} \\
\hline & & $3 / 22$ & $0.122 / 2.682$ & & \\
\hline \multirow{3}{*}{10} & \multirow{3}{*}{$3.248 \times 2.034=6.605$} & $4 / 11$ & $0.176 / 1.937$ & \multirow{3}{*}{1.24} & \multirow{3}{*}{81.2} \\
\hline & & $5 / 11$ & $0.163 / 1.788$ & & \\
\hline & & $6 / 11$ & $0.149 / 1.639$ & & \\
\hline
\end{tabular}
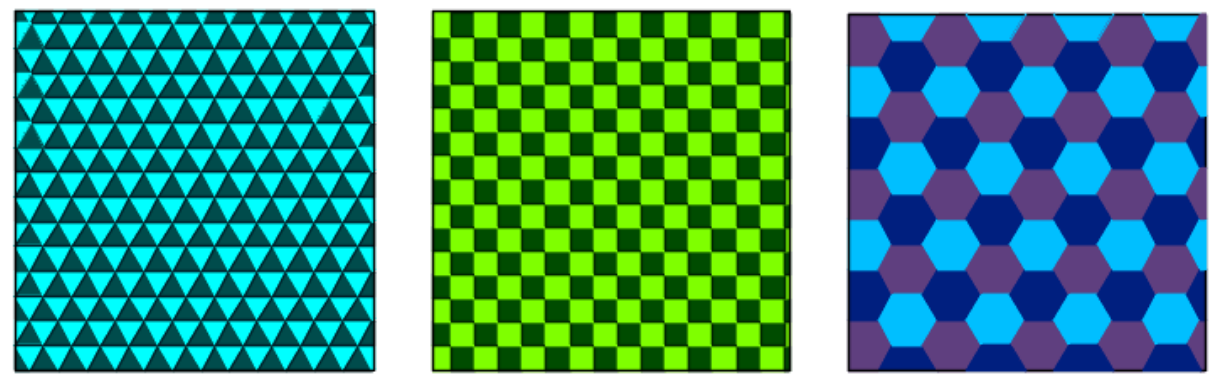

Fig. 11. Examples of proper tiling of a plain.

Figures 12, 13 presents various options of such a tiling for the cylindrical structure shown in Figure 2.

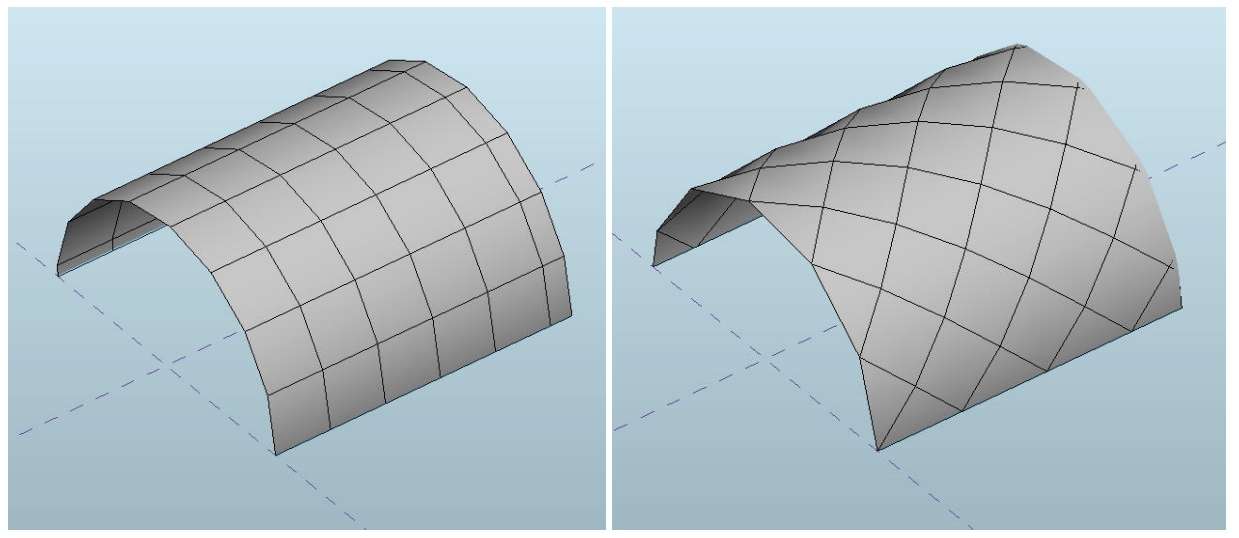

Fig. 12. Examples of tiling a cylindrical surface with regular polygons.

The presented parquet tiling is suggested to be made of sheet material and, with small widths of the structure, it is allowed to produce them not in pyramidal but in prismatic shape, which greatly facilitates the cutting process. The packing density of such cavities will be close to $100 \%$, which will significantly reduce material waste. 

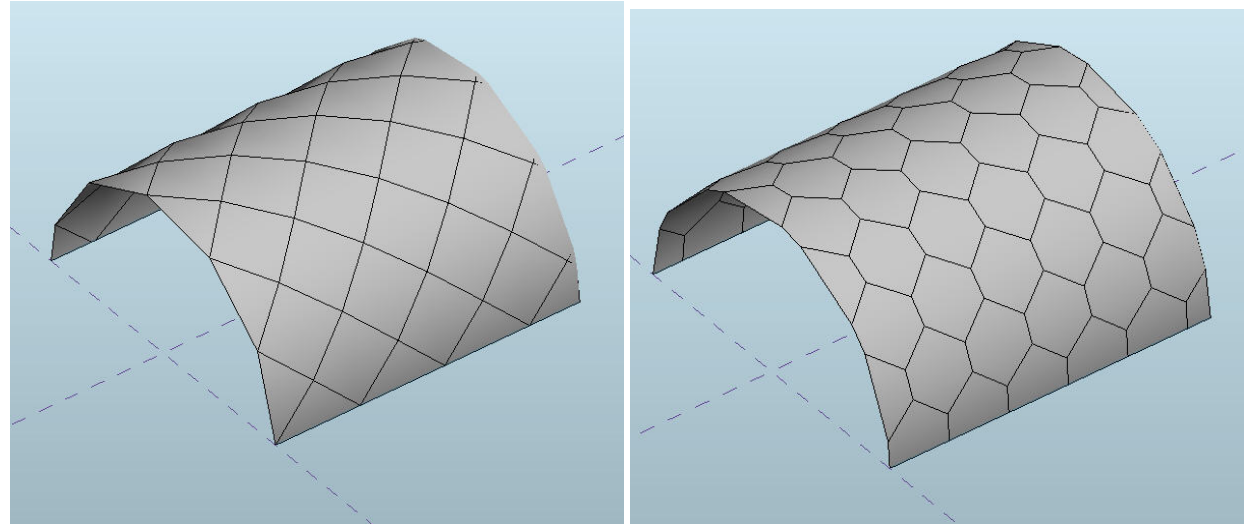

Fig. 13. Examples of tiling a cylindrical surface with regular polygons.

\section{Conclusions}

The problem of creating a technology for manufacturing polystyrene inserts for the erection of cylindrical shells has been solved. At the same time we achieved reducing the waste while cutting a flat rectangular sheet of expanded polystyrene and obtaining the minimum number of elements in the assortment for manufacturing triangular inserts used to produce a screen that provides shotcreting curvilinear reinforced concrete structures with the method of sprayed concreting. The obtained results confirm the effectiveness of using lightweight "Monofant" system designs that have a reduced width of not more than $40-50 \%$ from the structures with solid width.

\section{References}

1. C. Albrecht, Proceedings of The 9th fib International PhD Symposium in Civil Engineering, 85-90 (2012)

2. M. Mota, Concrete International, 32, 41-45 (2010)

3. A. Churakov, Construction of Unique Buildings and Structures, 6, 70-88 (2014)

4. O. Meneiliuk, K. Shavva, V. Taran, Modern Industrial and Civil Construction, 9, 221229 (2013)

5. V. Shmukler, Y. Klymov, M. Burak, Framework of hollow core types (Golden Pages, Kharkiv, 2008)

6. S. Bugayevskiy, Building Construction, 78, 478-586 (2013)

7. V. Babaev, V. Shmukler, S. Bugayevskiy, V. Nikulin, Journal of Civil Engineering and Construction, 5, 143-156 (2016)

8. V. Shmukler, S. Bugayevskiy, V. Herasymenko, O. Stefan, Mat. III Int. Sc. Materials III International Scientific Conference "Safety in transport and manufacturing education, science and practice", 282-289 (2016)

9. V. Shmukler, V. Babaev, S. Bugayevskiy, A. Bih, Method of construction of elements of structures of curvilinear shape. Patent of Ukraine № 113669 (2017) 